\title{
Reliability Tests on SAC-xMn Solder Alloys
}

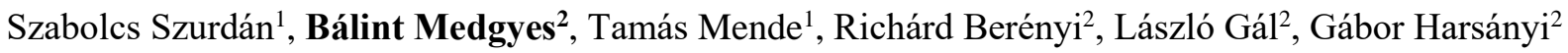 \\ 1)University of Miskolc, \\ Faculty of Materials Science and Engineering, Miskolc, Hungary \\ ${ }^{2}$ Department of Electronics Technology \\ Budapest University of Technology and Economics \\ Budapest, Hungary \\ medgyes@ett.bme.hu
}

\begin{abstract}
Different Sn based micro-alloyed solder alloys with manganese content were developed for the electronic industry as a possible cost-effective candidates. The commonly used $\mathrm{SnAg3Cu0.5} \mathrm{(SAC305)} \mathrm{lead-free} \mathrm{solder} \mathrm{alloy} \mathrm{applied} \mathrm{as} \mathrm{a} \mathrm{reference.} \mathrm{As} \mathrm{a} \mathrm{first} \mathrm{step,}$ various technological parameters tested from the solder alloy-manufacturing point of view. During the reliability investigations of the solder alloys, Vickers hardness, tensile strength and shear force tests were carried out. The results show that Mn content SAC alloys are useful in the electronics technology especially in those fields, where the high reliability is not required.
\end{abstract}

Keywords-SAC solder alloy, reliability, mechanical tests.

\section{INTRODUCTION}

Nowadays the electronic industry manufacturing even smaller and smaller devices with minimum weight and with maximum signal propagation speed next to cost effectiveness. Most of the electronic assemblies are produced by stencil printing and reflow soldering methods. Therefore, the development of the soldering materials has also a high importance. Different technological aspects have to considered related to solder materials: electrical conductivity, mechanical properties, melting point, voiding and other reliability behaviors. The first widely used type of the solder materials were the lead-bearing solder alloys. Due to the RoHS and WEEE restrictions lead-bearing solder alloys had to be replaced with lead-free ones. There are already many candidates, however the prize and the key technological parameters have to be still improved related to lead-free solder alloys [1 - 3]. Some technological parameters which should be improved: melting point, surface wetting behavior, void formation, mechanical strength, etc. Furthermore, various failure types were also detected in the solder joints after lead-free reflow soldering processes [4 - 6]. One of the most widely used lead-free solder alloy types are the Sn-Ag-Cu (SAC) ternaries [7-9]. One of the development trends of the SAC alloys is tend to the lower silver content to reduce the market prize [10-12]. So, instead of the high Ag content so called micro-alloyed elements were applied such as: $\mathrm{Ni}, \mathrm{Co}, \mathrm{Fe}, \mathrm{Sb}$, etc. The general aim of the micro-alloyed lead-free solder alloys is the improvement of the key technological parameters compare to traditional SAC alloys next low prizes. The so called technological window had to be done also wider, e.g. with the optimization of the temperature values during crystallization processes [13].

In the present study we have prepared different Mn-doped low Ag SAC alloys and then various reliability investigations were carried out, where the reference alloy was the widely used Sn96.5Ag3.0Cu0.5 (SAC305) type.

\section{EXPERIMENTAL}

\section{A. Preparation of the Lead-free Solder Alloy Samples}

The solder alloys used in this experiment were prepared in a $300 \mathrm{~kg}$ graphite vessel, where the first step was the preparation of the SAC0307 type as base alloy. Afterwards, the doping process (micro-alloying) of Mn into SAC0307 was carried out. The microalloying element was placed into bottom side of the graphite vessel and all of the chemical elements were melted at $800{ }^{\circ} \mathrm{C}$ and 3 hours. During the 3 hours heat annealing, the manganese elements were also alloyed into the SAC base alloy. Finally, the homogeneity of the Mn micro-alloyed SAC0307 alloy was reached using a graphite mixer tool. The exact chemical composition of the various Mn-doped SAC0307 alloy types can be seen in Table 1 . 
TABLE I. I ELEMENTAL COMPOSTION OF THE SOLDER ALLOYS IN WT\%

\begin{tabular}{|l|l|l|l|c|}
\hline \multicolumn{1}{|c|}{ Alloy Type } & Sn & Ag & Cu & Mn \\
\hline SAC0307Mn0.1 & $\mathrm{R}$ & 0.35 & 0.77 & 0.08 \\
\hline SAC0307Mn0.4 & $\mathrm{R}$ & 0.36 & 0.8 & 0.49 \\
\hline SAC0307Mn0.7 & $\mathrm{R}$ & 0.4 & 0.82 & 0.69 \\
\hline SAC305 & $\mathrm{R}$ & 3.05 & 0.52 & - \\
\hline
\end{tabular}

\section{B. Reliability tests}

1) Mechanical test of the solders alloys

Firstly, different type of mechanical tests were carried out. Vickers test was applied using an Instron Wilson Tukon type 2100 B equipment with $0.3 \mathrm{~kg}$ load and $10 \mathrm{sec}$ as a testing time. At least five measurements were carried out in each cases. The measured data were collected into Figure 1.

\section{a) Hardness test of the solder alloys}

In can be seen in Figure 1, that the different types of Mn-doped SAC alloys showed no significant changes in terms of hardness. It can be also seen, that SAC0307Mn0.7 type have about $30 \%$ lower Vickers hardness compare to SAC305. This significant difference can lead back to the Ag content differences between reference and Mn-doped SAC alloys.

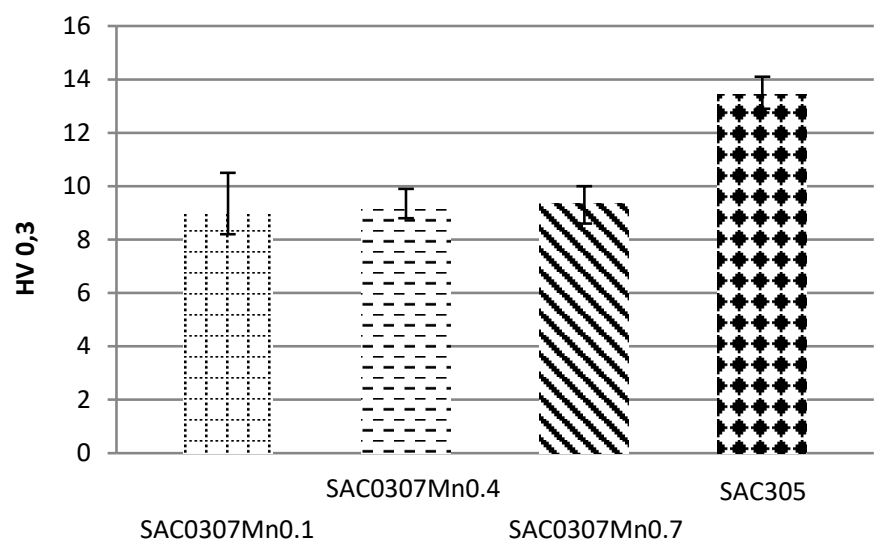

Fig. 1. Vickers hardness of Mn-doped SAC alloys.

b) Tensile strength test of the solder alloys

Standardized solder alloy samples were manufactured according to DIN-EN-50125. The dimension of the standard samples can be seen in Figure 2. The tensile strength tests were carried out using an Instron 5982 type universal equipment at room temperature. Uniaxial tensile stress was applied with fixed $3 \mathrm{~mm} / \mathrm{min}$ pull velocity in all cases.

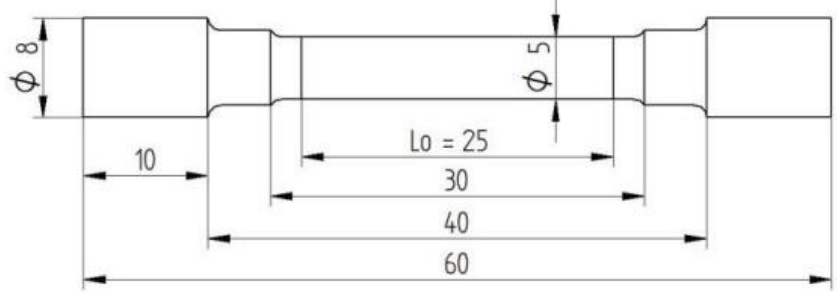

Fig. 2. Dimension of the test sample used in tensile strenght test [mm]. 
c) Shear force test of the Solder Joints

Our next goal was to carry out shear force tests using reflow soldering method, which simulates the mass production method in the electronic industry.

There was a problem with how to place on the solder material onto the surface of the printed wiring board (PWB) that we also produced using conventional subtractive technology. The most controllable mounting technology would have been stencil printing and reflow soldering using solder paste, but unfortunately we could not made such a small amount of solder paste from the Mn-doped SAC alloys. Only wire form of the solder alloys (Table 1) were available. The PWB test samples were $38 * 36 \mathrm{~mm}$ plates using $1 \times 1$ $\mathrm{mm}$ pads coved by immersion silver (iAg) surface finish. The solder alloys (collected in Table 1) were manufactured in wire form with diameter of $1 \mathrm{~mm}$. The wires were cut into well-defined pieces using a hand-held scissors. The selection of the catted solder wires was made by the randomly.

The solder wires were put onto the pads of the PWB in the following steps:

- Cleaning of PWB using isopropyl alcohol (IPA)

- Appling flux (type X33-125) on the iAg pads

- Placing solder alloy wires onto the iAg pads

This was followed by the resistor placement using 0 Ohm surface mount resistors (size: 0603). The placement was performed with a SMT Systems DIMA pneumatic implanter.

At least 250 measurements were carried out in each cases. The reflow soldering process was carried out with an Euro Circuits electric infrared re-melting (ReFlow) equipment, while the temperature values were recorded on a computer to obtain the temperature profile over the time. The same heat profile was applied for all SAC alloys.

In order to qualify the solder joints, the resistance values were measured using a Hewlett Packard 34401A multimeter (4-wire measurement method). The shear stress tests of the solder joints was also investigated using a Dage 2400 shear force meter (Figure 3). The tests were carried out first after reflow soldering (as reflowed), after 190 hours and finally 360 hours with aging at $80{ }^{\circ} \mathrm{C}$.

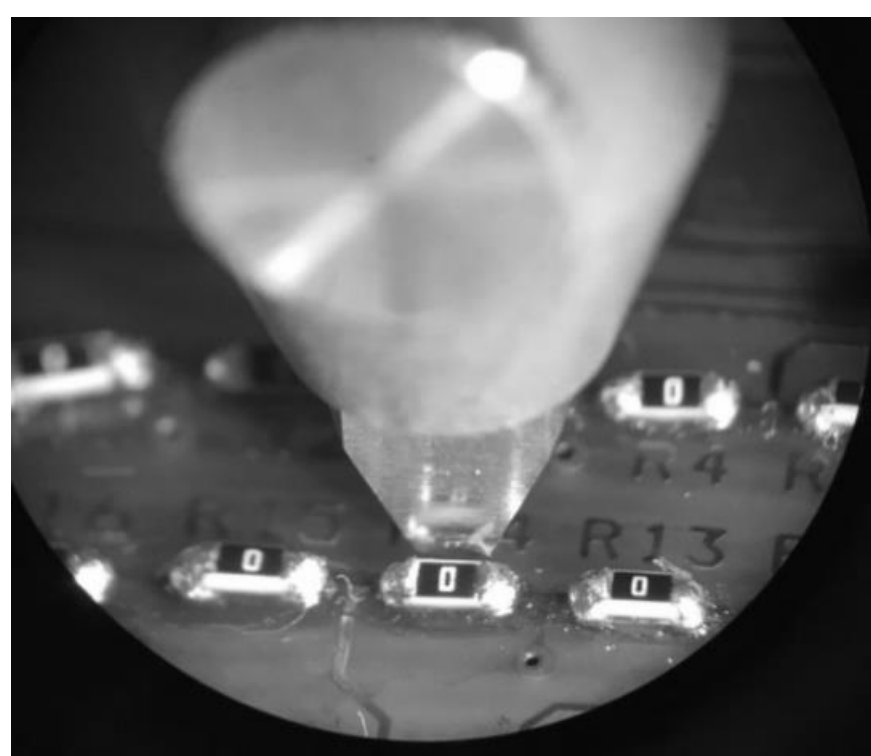

Fig. 3. Shear force test in case of 0 Ohm resistors (size: 0603).

\section{RESULTS AND DISCUSSION}

The results show (Fig. 4) that the tensile strength and the conventional yield strength values increased for the $0.1 \%$ and $0.4 \%$ manganese SAC0307 alloys, and after the addition of the manganese 0.3\% (SAC0307Mn0.7), they decrease slightly. Elongation values were the highest for $0.1 \%$ manganese content and then decrease as a result of further alloying. During the test, at least three tensile specimens per alloy were tested. The diagram shows that the SAC0307Mn0.4 tensile strength result is similar to that of the SAC305 alloy. 


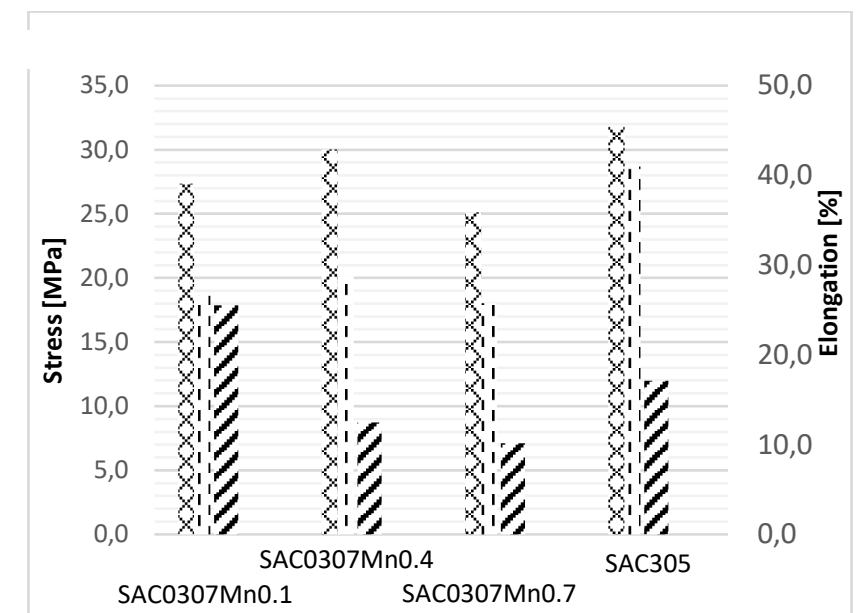

Fig. 4. Tensile Strength (Rm), conventional yield point (Rp0.2) and elongation respectivly.

The results of the shear force test are summarized in Figure 5.

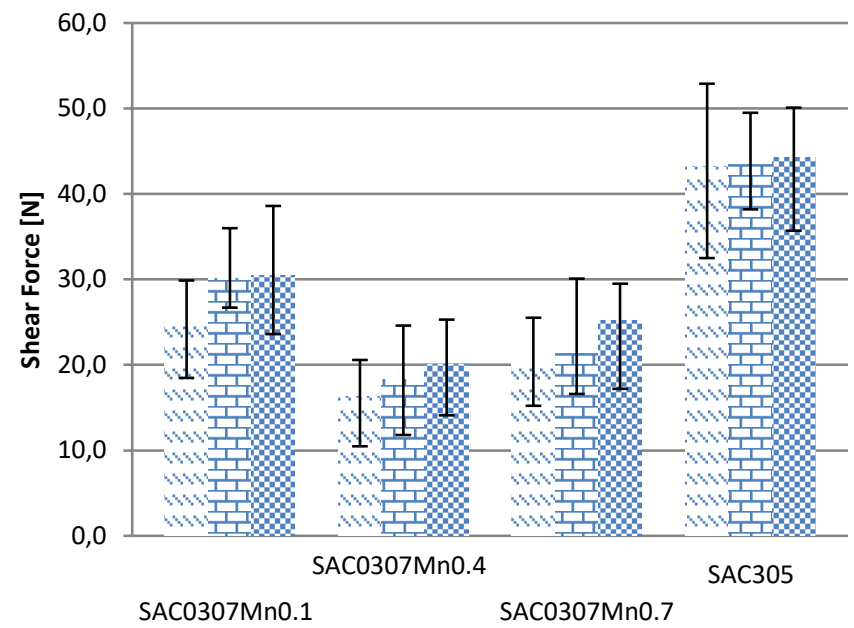

Fig. 5. Results of shear strength measurements of solder alloys as reflowed, after 190 hours at $80^{\circ} \mathrm{C}$ and after 360 hours at $80^{\circ} \mathrm{C}$ respectively.

It should be noticed that shear strength values increase slightly with aging. In the case of manganese-containing alloys, a greater increase trend of shear force over aging time was observed compare to SAC305. For the SAC0307Mn0.1 alloy, shear strength increased by nearly $20 \%$ from the initial $25.4 \mathrm{~N}$ after aging at $80^{\circ} \mathrm{C}$ for 190 hours and increased by a further $1 \%$ after another 170 hours of aging, compared to the increase tendency in SAC305 alloy. The SAC0307Mn0.4 alloy showed $16.3 \mathrm{~N}$ after soldering, increased 12\% after 190 hours of aging and a further 9\% after 360 hours of aging. The values of the SAC305 alloy are higher, according to the results of the experiment after reflow soldering, the shear force was $43.2 \mathrm{~N}$, which changed slightly with aging, after 0.5 hours it was $0.5 \%$, and after 360 hours aging only $2 \%$. Lee et al. [14] also investigated this property and found similar results. Other researchers [15] have shown that the low silver content of manganese alloy increases the IMC layer thickness, however, after longer aging cycles, the thickness increases slightly and the metal structure remains finer, resulting in relative increased shear strength. 


\section{CONCLUSIONS}

In our work, the possibility of manganese micro-alloying in case of SAC lead-free alloys and conducted various reliability tests were investigated. Our aim was to investigate the impact of manganese content on low-silver micro-alloyed lead-free SAC alloys, considering both mechanical properties and economical aspects as well. The results of the hardness tests showed that the addition of manganese to the SAC solder alloy could reduce the hardness. The tensile strength test results showed that the addition of Mn to the lead-free SAC alloy results in a slight decrease. After reflow soldering, it was found that the alloys we made did not reach the mechanical strength than that of the SAC305 alloy. However, examination of the post-aging state of the soldered joints was good agreement with earlier literature [5]. Namely, over a longer aging period, the mechanical strength of Mn-containing solder joints is greater compare to SAC305 alloys. Although the mechanical properties of manganese alloyed SAC alloys were generally worse than those of SAC305, the minimum soldering requirement was exceeded. Taking into account both economic and mechanical properties, we recommend the industrial application of SAC0307 solder alloy with manganese micro-alloying in case of commercial electronics without any high reliability requirements.

\section{ACKNOWLEDGMENT}

The work reported in this paper was supported by the Pro Progressio Foundation (Hungary). The authors would like to thank the support for the National Research, Development and Innovation Office NKFIH, PD 120898 as well. The research reported in this paper was also supported by the Higher Education Excellence Program of the Ministry of Human Capacities in the frame of Nanotechnology and Materials Science research area of Budapest University of Technology and Economics (BME FIKP-NAT).

\section{REFERENCES}

[1] U. Büyök and N. Marasli, "The microstructure parameters and microhardness of directionally solidified Sn-Ag-Cu eutectic alloy", Journal of Alloys and Compounds 485, pp. $264-269,2009$

[2] Molnár A., Kardos I., Molnár I. és Gácsi Z., “Az ezüsttartalom hatása ólommentes forraszanyagok tulajdonságaira”, Bányászati és Kohászati Lapok, 147. évfolyam 2014/2. szám 17- 20.

[3] B. Horváth, “Az RoHS direktívái és a tiltott anyagok vizsgálata XRF berendezéssel”, Diplomamunka Budapesti Műszaki Egyetem 2008. Budapest

[4] B. Medgyes, B. Illés, G. Harsányi, Electrochemical Migration of Micro-alloyed Low Ag Solders in NaCl Solution, PERIODICA

[5] A. Géczy, D. Straubinger, T. Hurtony, O. Krammer, A. Kovács, "Investigating current density in the lead free solder joints of surface mounted resistors with experimental approach", IEEE, 40th International Spring Seminar on Electronics Technology (ISSE), 2017, pp. 1-6

[6] B. Illés, B. Horváth, Whiskering Behaviour of Immersion Tin Surface Coating, MICROELECTRONICS RELIABILITY 53 (2013) $755-760$

[7] M. Wang, J. Wang. H. Feng, W. Ke, "Effects of microstructure and temperature on corrosion behavior of Sn-3.0Ag-0.5Cu lead-free solder", J Mater Sci: Mater Electron, 2012, Vol 23, pp. 148-155

[8] F. Rosalbino, E. Angelini, G. Zanicchi, R. Carlini, R. Marazza, "Electrochemical corrosion study of Sn-3Ag-3Cu solder alloy in NaCl solution", Electrochimica Acta, 2009, Vol 54, pp. 7231-7235

[9] L. Hua, C. Yang, "Corrosion behavior, whisker growth, and electrochemical migration of $\mathrm{Sn}-3.0 \mathrm{Ag}-0.5 \mathrm{Cu}$ solder doping with In and $\mathrm{Zn}$ in NaCl solution", Microelectronics Reliability, 2011, Vol 51, pp. 2274-2283

[10] N. Mookam, K. Kanlayasiri, "Evolution of Intermetallic Compounds between Sn $\{0.3 \mathrm{Ag}\{0.7 \mathrm{Cu}$ Low-silver Lead-free Solder and Cu Substrate during Thermal Aging”, J. Mater. Sci. Technol., Vol 28(1), 2012, pp 53-59

[11] Y. Liu, F. Sun, P. Zou, "Shear Strength and Interfacial Microstructures of Low-Ag SAC/Cu and SAC-BiNi/Cu Solder Joints", International Symposium on Advanced Packaging Materials (APM), 2011, pp. 186-189

[12] F. Cheng, F. Gao, J. Zhang, W. Jin, X. Xiao, “Tensile properties and wettability of SAC0307 and SAC105 low Ag lead-free solder alloys”, J Mater Sci, 2011, 3424-3429

[13] Óbudai Egyetem, levelező tagozat Elektronikai technológia előadás, www.uni-obuda.hu/grollerg/Elektrinikaitechnologia/Prezentaciok/levelezo-tav-16/4szereles.pdf / download: 2017. 02.11.

[14] Li-Wei Lin, Jenn-Ming Song, Yi-Shao Lai, Ying-Ta Chiu, Ning-Cheng Lee, Jun-Yen Uan, "Alloying modification of Sn-Ag-Cu solders by manganese and titanium", Microelectronics Reliability 49 (2009) 235-241

[15] Jenn-Ming Song, Yao-Ren Liu, Yi-Shao Lai, Ying-Ta Chiu, Ning-Cheng Lee, "Influence of trace alloying elements on the ball impact test reliability of SnAgCu solder joints", Microelectronics Reliability 52 (2012) 180-189 